\title{
Microwave-assisted extraction of anthocyanin from Chinese bayberry and its effects on anthocyanin stability
}

\author{
Wenkai DUAN ${ }^{1,2}$, Shiping $\mathrm{JIN}^{2}$, Guofu $\mathrm{ZHAO}^{2}$, Peilong SUN ${ }^{1 *}$
}

\begin{abstract}
Anthocyanins are present in high concentrations in Chinese bayberry, Myrica rubra Sieb. \& Zucc. Herein, a microwave-assisted extraction was used to extract the anthocyanins from Chinese bayberry. The HPLC chromatogram of the extracts showed that the anthocyanin components were slightly hydrolysed during the extraction process. Further experiments confirmed that microwave irradiation slightly hydrolysed cyanidin-3-O-glucoside to cyanidin, but did not significantly influence the antioxidant activity of the extracts. Optimized extraction conditions for total anthocyanin content were a solid-to-liquid ratio, extraction temperature, and extraction time of $1: 50,80^{\circ} \mathrm{C}$, and $15 \mathrm{~min}$, respectively. Under these conditions, the anthocyanin content was $2.95 \pm 0.08 \mathrm{mg} \cdot \mathrm{g}^{-1}$, and the antioxidant activity yield was $279.96 \pm 0.1 \mu \mathrm{mol} . \mathrm{g}^{-1}$ Trolox equivalent on a dry weight basis. These results indicated that microwave-assisted extraction was a highly efficient extraction method with reduced processing time. However, under some extraction conditions it could damage the anthocyanins. These results provide an important guide for the application of microwave extraction.
\end{abstract}

Keywords: Chinese bayberry; anthocyanin extraction; microwave-assisted extraction; cyanidin-3-O-glucoside; anthocyanin stability.

Practical Application: This study showed that microwave irradiation would slightly hydrolysed cyanidin-3-O-glucoside to cyanidin, it provide an important guide for the application of microwave extraction.

\section{Introduction}

Chinese bayberry, Myrica rubra Sieb. \& Zucc., is one of the six Myrica species native to China (Chen et al., 2004), and is noted for the attractive red colour of its fruits. Many pigments were extracted, identified, and characterized from different natural sources, especially red fruit extracts, for their safe use as colorants. Anthocyanins are among the most broadly distributed pigment groups in plants, and are present at high concentration in Chinese bayberry. The major anthocyanin present in bayberry fruits was identified as cyanidin-3-O-glucoside (C-3-G), which represents more than $95 \%$ of the total pigment content (Bao et al., 2005). Anthocyanins from Chinese bayberry can protect $\beta$-cells from oxidative-stress mediated injury (Zhang et al., 2011) and contribute to promoting good health and reducing the risk of chronic disease (Philpott et al., 2004).

Extraction is the first step in the commercial isolation of anthocyanins. Conventional extraction techniques for solid matrices include the well-known Soxhlet extraction, sonication, and blending. Although efficient extractions can be achieved using these simple techniques, they present major drawbacks. In particular, they feature long extraction times (especially for Soxhlet extraction), high solvent consumption, and low temperatures, and they are not yet readily automated (Heemken et al., 1997; Egizabal et al., 1998). Over the last decade, new techniques have emerged that will supersede traditional techniques. These include supercritical fluid, pressurized fluid, and microwave-assisted extraction (Schantz et al., 1997; Lopez-Avila et al., 1994).

Microwave-assisted extraction (MAE) has been demonstrated to be a fast and efficient unconventional extraction method that was developed for extracting analytes from solid matrixes, in particular, secondary metabolites from plant material (Kaufmann \& Christen, 2002), such as saponins from ginseng (Kwon et al., 2003; Vongsangnak et al., 2004), glycyrrhizic acid from licorice root (Pan et al., 2000), anthocyanins in red raspberries (Sun et al., 2007), and alkaloids from the seeds of Lupinus mutabilis (Ganzler et al., 1990). Microwave energy is a non-ionizing radiation that results in molecular movement by migration of ions and rotation of molecules with permanent dipoles in liquids, without altering their molecular structures unless the temperature is too high (Kaufmann \& Christen, 2002). Microwave extraction greatly reduces solvent consumption and extraction times and improves extraction efficiency (Eskilsson \& Björklund, 2000).

The stability of anthocyanin is very important during the extraction, and is influenced by numerous factors, including temperature, $\mathrm{pH}$, water activity, and light (Amr \& Tamini, 2007). Recently, a study suggested that vitamin $\mathrm{C}$ was unstable under microwave conditions (Yuan et al., 2009), whereas some confirmed that microwaving preserved bioflavonoid content 
(Gorinstein et al., 2008; El-Adawy, 2002). Thus, the effect of microwave irradiation on the stability of anthocyanin needs to be further studied.

Herein, MAE was used to extract antioxidant compounds from Chinese bayberry. The aim of this work was to elucidate the optimal extraction conditions and evaluate whether it affects the structure or antioxidant activity of the extracted compounds.

\section{Materials and methods}

\subsection{Chemicals and reagents}

Cyanidin-3-O-glucoside standard was obtained from Extrasynthèse (Genay, France). 6-Hydroxy-2,5,7,8-tetramethylchroman-2- carboxylic acid (Trolox) and 2,2-Diphenyl-1picrylhydrazyl (DPPH) were purchased from Sigma Chemical Co. (St. Louis, MO, USA). Acetonitrile (HPLC grade), formic acid, ethanol, and hydrochloric acid (analytical grade) were purchased from Shanghai Chemical Reagent Company (China). All solutions were prepared using distilled-deionized water.

\subsection{Plant material}

Myrica rubra Sieb. \& Zucc. cv. Dongkui belongs to the genus Myrica in the family Myricaceae. Mature Chinese bayberry fruits were obtained from a fruit market in Taizhou, Zhejiang Province, China in June 2013. The samples were immediately dried in a lyophilizer (Labconco, Kansas City, USA), and then ground and sifted for homogenization before storing at $-80^{\circ} \mathrm{C}$ to avoid the degradation of the compounds.

\subsection{Microwave-assisted extraction}

The microwave-assisted extraction was performed using a microwave accelerated reaction system (MARSXpress, CEM Cooperation, Matthews, NC, USA) with a microwave power of $800 \mathrm{~W}$, equipped with a digital timer and temperature controller.

The dried bayberry powder ( $0.50 \mathrm{~g})$ was accurately weighed, placed in a tube, and mixed with an appropriate amount of extracting solvent (1\% $\mathrm{HCl}$ in 95\%ethanol). After thorough mixing, the tube containing the suspension was irradiated, using a predetermined extraction time and temperature, in the microwave device. After the microwave extraction, the sample was centrifuged at $8000 \mathrm{rpm}$ for $10 \mathrm{~min}$, and then the supernatant was collected and all samples were diluted to the same volume. All of the samples were filtered through a $0.45-\mu \mathrm{m}$ syringe filter (Pall Life Sciences, Ann Arbor, MI, USA).

\subsection{Determination of anthocyanin content}

The total anthocyanin content of extracts was determined using a modified $\mathrm{pH}$ differential method described previously (Kim et al., 2003; Zhou et al., 2009). A general spectrophotometer (T6 New Century, Purkinje General Instrument Co., Beijing, China) was used to measure absorbance at 520 and $700 \mathrm{~nm}$ in buffers at $\mathrm{pH}$ 1.0 and 4.5. The absorbance measurements were converted into total milligrams of cyanidin-3-glucoside per gram dry weight of bayberry using the molar extinction coefficient, $\varepsilon=26900 \mathrm{~L} \cdot \mathrm{mol}^{-1} \cdot \mathrm{cm}^{-1}$, and absorbance of $\mathrm{A}=\left[\left(\mathrm{A}_{520}-\mathrm{A}_{700}\right)_{\mathrm{pH} 1.0}-\left(\mathrm{A}_{520}-\mathrm{A}_{700}\right)_{\mathrm{pH} 4.5}\right]$. The data were reported as mean \pm standard deviation for three replications.

\subsection{HPLC-DAD-ESI-MS analysis}

HPLC-DAD-ESI-MS analysis was performed using a Waters platform system, which was composed of a Micromass QUATTRO MICROTM API mass spectrometer, a Waters 600 pump system, and a Waters 2996 photodiode array detector (Waters Corp., Milford, MA, USA). Data were collected and processed on a personal computer running MassLynx software (Micromass, a division of Waters Corp., Beverly, MA, USA). Aliquots of bayberry extracts $(20 \mu \mathrm{L})$ were resolved using a SUNFIRE C-18 column $(250 \times 4.6 \mathrm{~mm}, 5 \mu \mathrm{m}$, Waters Corp., Milford, MA, USA), where solvent A was $0.05 \%(\mathrm{v} / \mathrm{v})$ formic acid in water, and solvent $\mathrm{B}$ was $0.05 \%(\mathrm{v} / \mathrm{v})$ formic acid in acetonitrile, and the flow rate was $0.7 \mathrm{~mL} \cdot \mathrm{min}^{-1}$. The injection volume was $20 \mu \mathrm{L}$, and the detection wavelengths was $520 \mathrm{~nm}$. The elution system was: $0-5 \mathrm{~min}=5 \%$ solvent $\mathrm{B}, 5-10 \mathrm{~min}=$ linear gradient from $5-10 \%$ of solvent $\mathrm{B}, 10-25 \mathrm{~min}=$ linear gradient from $10-90 \%$ of solvent $\mathrm{B}$, and 25-50 $\mathrm{min}=90 \%$ solvent $\mathrm{B}$. Cyanidin-3-O-glucoside was used as a standard for quantitation of cyanidin-3-O-glucoside content, the ratio of cyanidin-3-O-glucoside to total anthocyanin was expressed to total anthocyanin content divided by the content of cyanidin-3-O-glucoside.

Mass spectra were obtained using electrospray ionization in positive ion mode. The following ion optics were used: capillary $=3.88 \mathrm{kV}$ and cone $=60 \mathrm{~V}$. The source block temperature was $90^{\circ} \mathrm{C}$ and the desolvation temperature was $150^{\circ} \mathrm{C}$. Continuous mass spectra were recorded over $\mathrm{m} / \mathrm{z}$ 50-800 with a scan time of $1 \mathrm{~min}$ and interscan delay of $0.15 \mathrm{~s}$.

\subsection{Evaluation of antioxidant activity using the DPPH method}

The scavenging effects of the samples on the 2,2-diphenyl-1picrylhydrazyl (DPPH) radical were monitored using the previously reported method (Bao et al., 2005; Zhou et al., 2009). In summary, $0.1 \mathrm{~mL}$ of the diluted sample was added to $3.9 \mathrm{~mL}$ of $0.1 \mathrm{mmol} \cdot \mathrm{L}^{-1}$ $\mathrm{DPPH}$ solution. It was vortexed and then allowed to react at ambient temperature for $30 \mathrm{~min}$ in the dark. The absorbance at $517 \mathrm{~nm}$ was measured using a spectrophotometer. A calibration curve was constructed for the decrease in absorbance based on trolox concentration, and $0.1 \mathrm{~mL}$ of $95 \%$ ethanol was used as a control. The inhibition ratio was calculated as follows:

Inhibition ratio $(\%)=100 \times\left(A_{o}-A_{s}\right) / A_{o}$, where $A_{o}$ and $A_{s}$ represent the absorbance of the control and sample solutions, respectively. The antioxidant activity was expressed as $\mu \mathrm{mol}$ Trolox equivalent $\mathrm{g}^{-1}$ dry weight.

\subsection{Experimental design and statistical analysis}

A three-level three-factor Box-Behnken design was selected to evaluate the combined effect of three independent variables: solid to liquid ratio, extraction temperature, and time, which were coded as $\mathrm{X}_{1}, \mathrm{X}_{2}$, and $\mathrm{X}_{3}$, respectively (Table 1 ). 
In total, 15 experiments with three replicates at the centre were employed. The response surface methodology (RSM) was used to determine the optimum conditions for the extraction of anthocyanins from Chinese bayberry. The experimental design and statistical analysis were performed using Stat-Ease software (Design-Expert 7.0.10 Trial, Delaware, USA). The generalized second order polynomial model used for the response surface analysis was as follows:

$Y=b_{0}+\sum_{i=1}^{3} b_{i} X_{i}+b_{i i} \sum_{i=1}^{3} X_{i}^{2}+\sum_{i=1}^{2} \sum_{m=i+1}^{3} b_{i m} X_{i} X_{m}$

where the response function, Y, was partitioned into linear, quadratic, and interactive components, $\mathrm{b}_{0}, \mathrm{~b}_{\mathrm{i}}, \mathrm{b}_{\mathrm{ii}}$, and $\mathrm{b}_{\mathrm{im}}$ are defined as the constant, linear coefficient, quadratic coefficient, and cross-product coefficient, respectively, and $\mathrm{X}_{\mathrm{i}}$ and $\mathrm{X}_{\mathrm{m}}$ are the levels of the independent variables. Analysis of variance (ANOVA) tables were generated, and the effect and regression coefficients of the individual linear, quadratic, and interaction terms were determined.

\section{Results and discussion}

\subsection{HPLC analysis of anthocyanins extracted from chinese bayberry}

Anthocyanins were extracted from Chinese bayberry using a microwave-assisted method. The HPLC chromatogram of the anthocyanins is shown in Figure 1. Peak 1 displayed at $m / z 287$, corresponding to the molecular of cyanidin, was assumed to be cyanidin according to the reported by Zhao et al. (2013). Peak 2 has an $\mathrm{m} / \mathrm{z} 449$ corresponding to $[\mathrm{M}]^{+}$, with a characteristic fragmentation $[\mathrm{M}-162]^{+}$at 287 corresponding to the cleavage of glucose, hence, it was assigned as cyanidin-3-O-glucoside. By comparing its HPLC retention time to a cyanidin-3-O-glucoside standard, peak 2 was further confirmed as cyanidin-3-O-glucoside. We suggest that cyanidin might be the hydrolysis product of cyanidin-3-O-glucose formed during the microwave-assisted extraction. Although it has been reported that malvidin-3-glucoside and malvidin-3,5diglucoside might hydrolyze to the products of anthocyanone, hydroxycoumarins and dihydroxy phenylacetaldehyde under microwave treatment (Ramirez et al., 2015), this finding imply that there may be other anthocyanin degradation pathway under different conditions, such as cyanidin, delphinidin and

Table 1. Code and actual levels of three variables.

\begin{tabular}{|c|c|c|c|c|c|}
\hline \multirow{2}{*}{ Independent variables } & \multirow{2}{*}{ Units } & \multirow{2}{*}{ Symbol } & \multicolumn{3}{|c|}{ Code levels } \\
\hline & & & -1 & 0 & 1 \\
\hline Solid to liquid ratio & $1: \mathrm{X}$ & $\mathrm{X}_{1}$ & 30 & 40 & 50 \\
\hline $\mathrm{T}$ & {$\left[{ }^{\circ} \mathrm{C}\right]$} & $\mathrm{X}_{2}$ & 40 & 60 & 80 \\
\hline
\end{tabular}
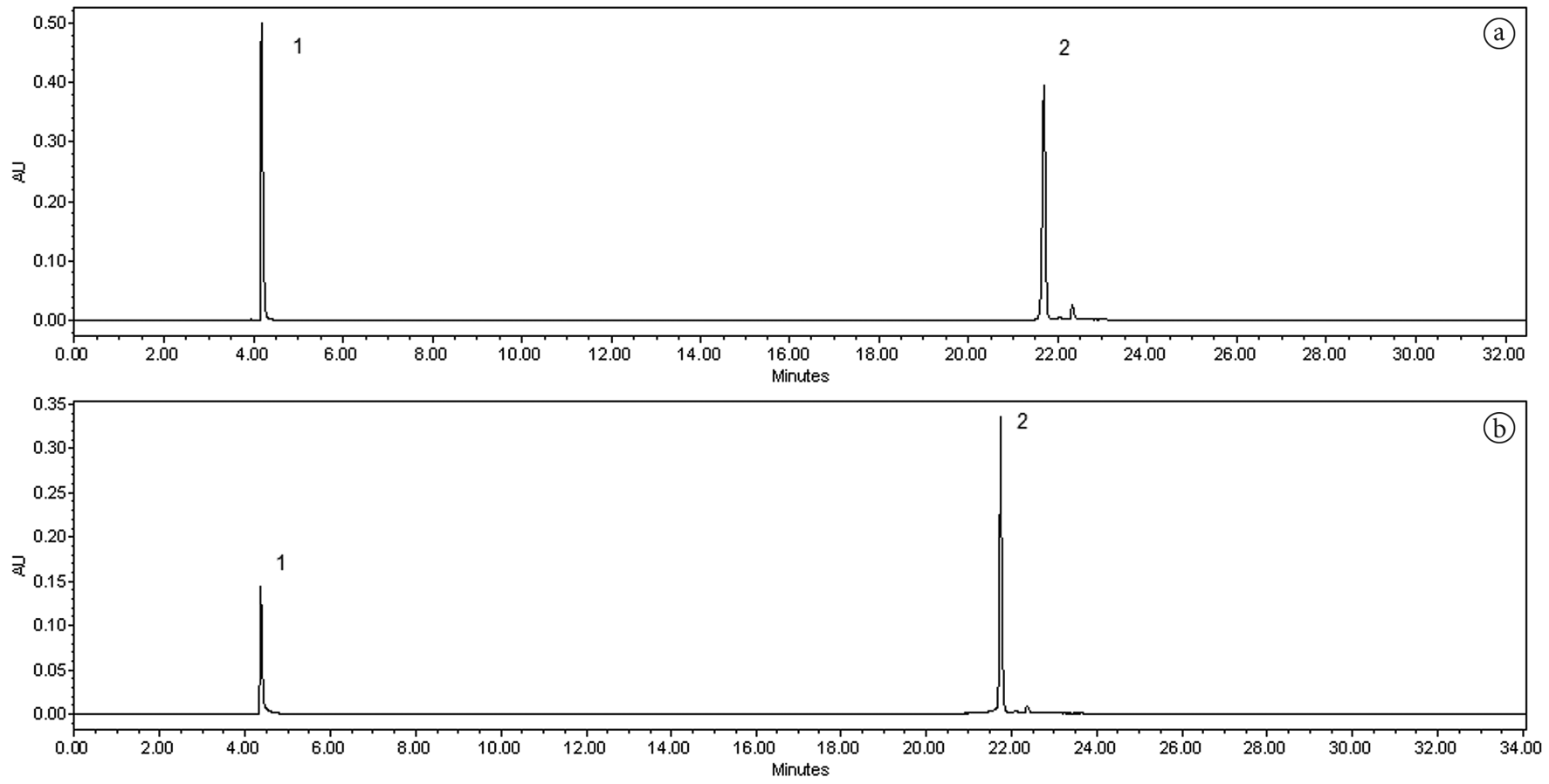

Figure 1. HPLC profile of the anthocyanin extracted from Chinese bayberry using a microwave-assisted method. $1=$ Cyanidin; $2=$ Cyanidin-3-O-glucoside (C-3-G). UV-Vis detection at $520 \mathrm{~nm}$. (a) under $80^{\circ} \mathrm{C}$ extract condition; (b) under $60^{\circ} \mathrm{C}$ extract condition. 
pelargonidin can be extracted from fresh floral and vegetative tissue by using $2 \mathrm{M} \mathrm{HCl}$ leaching (Des Marais \& Rausher, 2010).

\subsection{Effects of microwave irradiation on Cyanidin-3-O-glucose hydrolysis}

Cyanidin is an anthocyanin and is bound to glucose to form $\mathrm{C}-3-\mathrm{G}$, which is the main component of anthocyanins in the fruit of Chinese bayberry (Tanaka et al., 2008). Although it is well documented that there is no significant difference between the antioxidant activity of cyanidin and C-3-G (Kähkönen \& Heinonen, 2003), we used a C-3-G standard to evaluate the effect of microwaves on the hydrolysis and release of cyanidin and its antioxidant activity. A two-factor and two-level experimental design was conducted to evaluate the influence of temperature and extraction time on the hydrolysis of C-3-G. The results are shown in Table 2. Two-way ANOVA results showed that increasing the temperature increased the total anthocyanin content, but decreased the ratio of C-3-G to total anthocyanin, whereas it had no significant effect on the antioxidant activity of the extracts. Increasing the extraction time did not increase the antioxidant activity of the extracts or the total anthocyanin content, but significantly decreased the ratio of C-3-G to total anthocyanin, especially when extracting at $80^{\circ} \mathrm{C}$.

\subsection{Optimization of the microwave-assisted extraction conditions}

A three-level three-factor Box-Behnken design was selected to evaluate the combined effect of three independent variables: solid to liquid ratio, extraction temperature, and time on the yield of anthocyanins extracted from Chinese bayberry using a microwave-assisted method. The C-3-G and total anthocyanin contents in the microwave-assisted extract were determined, and the ratio of C-3-G to total anthocyanin was calculated. The antioxidant activity of the microwave-assisted extracts was also determined. These results are listed in Table 3.

A positive correlation between the total anthocyanins and the antioxidant activity $\left(R^{2}=0.8431\right.$, Figure 2$)$ was observed, which agrees with previous findings (Kähkönen \& Heinonen, 2003). Because C-3-G is hydrolysed into cyanidin in human bodies (Min et al., 2010), it is better to optimize the extraction

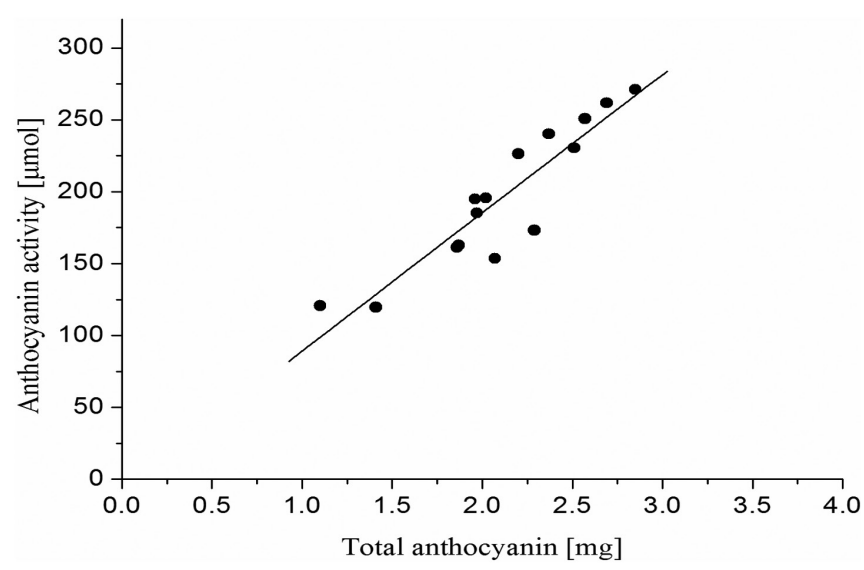

Figure 2. The correlation between total anthocyanin content and antioxidant activity $\left(R^{2}=0.8431\right)$.

Table 2. Effect of microwave irradiation on the hydrolysis of C-3-G.

\begin{tabular}{ccccc}
\hline & \multicolumn{3}{c}{$40^{\circ} \mathrm{C}$} & \multicolumn{2}{c}{$80^{\circ} \mathrm{C}$} & 15 min \\
\cline { 2 - 5 } & 5 min & $15 \min$ & $64.17 \pm 2.21$ & $64.60 \pm 0.96$ \\
DPPH [\%] & $60.73 \pm 1.36$ & $63.43 \pm 3.20$ & $28.67 \pm 0.58$ & $29.67 \pm 1.15$ \\
Total anthocyanin [mg.L ${ }^{-1}$ ] & $26.33 \pm 1.15$ & $26.67 \pm 1.15$ & $76.00 \pm 0.92$ & $48.00 \pm 1.15$ \\
\hline
\end{tabular}

Table 3. Response surface design and experimental data ${ }^{\mathrm{a}}$.

\begin{tabular}{|c|c|c|c|c|c|c|c|}
\hline Run & $\mathrm{X}_{1}$ & $\mathrm{X}_{2}$ & $\mathrm{X}_{3}$ & $\mathrm{C}-3-\mathrm{G}$ yield $\left[\mathrm{mg}^{-1} \mathrm{~g}^{-1}\right]$ & $\begin{array}{c}\text { Total anthocyanin yield } \\
{\left[{\left.\mathrm{mg} \cdot \mathrm{g}^{-1}\right]}\right.}\end{array}$ & C-3-G/total anthocyanin & $\begin{array}{c}\text { Total antioxidant } \\
\text { activity }^{\mathrm{b}}\left[\mu \mathrm{mol} \cdot \mathrm{g}^{-1}\right]\end{array}$ \\
\hline 1 & 1 & 0 & 1 & 1.97 & 2.85 & 0.69 & 271.07 \\
\hline 2 & 0 & 1 & -1 & 1.83 & 2.51 & 0.73 & 230.56 \\
\hline 3 & 1 & -1 & 0 & 0.73 & 1.10 & 0.66 & 120.78 \\
\hline 4 & 1 & 0 & -1 & 1.30 & 1.86 & 0.70 & 161.26 \\
\hline 5 & -1 & 0 & 1 & 1.70 & 2.20 & 0.77 & 226.38 \\
\hline 6 & 0 & -1 & -1 & 1.38 & 1.87 & 0.74 & 162.8 \\
\hline 7 & 0 & -1 & 1 & 1.39 & 2.07 & 0.67 & 153.56 \\
\hline 8 & -1 & 0 & -1 & 1.60 & 2.29 & 0.70 & 173.14 \\
\hline 9 & -1 & 1 & 0 & 1.77 & 2.37 & 0.75 & 240.24 \\
\hline 10 & 0 & 1 & 1 & 1.89 & 2.69 & 0.70 & 261.8 \\
\hline 11 & -1 & -1 & 0 & 0.90 & 1.41 & 0.64 & 119.68 \\
\hline 12 & 1 & 1 & 0 & 1.93 & 2.57 & 0.75 & 250.80 \\
\hline 13 & 0 & 0 & 0 & 1.43 & 1.97 & 0.73 & 185.24 \\
\hline 14 & 0 & 0 & 0 & 1.48 & 2.02 & 0.73 & 195.58 \\
\hline 15 & 0 & 0 & 0 & 1.37 & 1.96 & 0.70 & 194.92 \\
\hline
\end{tabular}

aYields and activities are based on dry weight. $\mathrm{X}_{1}, \mathrm{X}_{2}$ and $\mathrm{X}_{3}$ are defined in Table $1 .{ }^{\mathrm{b}}$ Antioxidant activity was expressed as $\mu$ mol of Trolox equivalent per $\mathrm{g}$ of dry weight. 
to target the total anthocyanin content if we are only concerned with their health benefits. However, the extraction conditions should be optimized to target the C-3-G content if purified $\mathrm{C}-3-\mathrm{G}$ from Chinese bayberry is required.

The total anthocyanin content was optimized using an RSM analysis. The polynomial equation of the quadratic model was as follows:

$\mathrm{Y}=1.98+0.014 \mathrm{X}_{1}+0.46 \mathrm{X}_{2}+0.16 \mathrm{X}_{3}+0.13 \mathrm{X}_{1} \mathrm{X}_{2}+0.27 \mathrm{X}_{1} \mathrm{X}_{3}-2.5$ $\times 10^{-3} \mathrm{X}_{2} \mathrm{X}_{3}-0.054 \mathrm{X}_{1}^{2}-0.067 \mathrm{X}_{2}^{2}+0.37 \mathrm{X}_{3}^{2}\left(F_{\text {model }}=7.32 ; p<0.05\right.$; $R^{2}=0.9295$ ), where $\mathrm{Y}, \mathrm{X}_{1}, \mathrm{X}_{2}$, and $\mathrm{X}_{3}$ are the total anthocyanin yield, solid to liquid ratio, extraction temperature, and extraction time, respectively.

The maximum total anthocyanin yield of $2.95 \mathrm{mg} \cdot \mathrm{g}^{-1}$ on a dry weight basis was obtained when using the optimal extraction conditions: solid to liquid ratio, extraction temperature, and time of $1: 50,80^{\circ} \mathrm{C}$, and $15 \mathrm{~min}$, respectively. The ANOVA statistics showed that the experimental data had correlation coefficient $\mathrm{R}^{2}=0.9295$ with the calculated model.

To confirm these results, Chinese bayberry powder was extracted in triplicate using the above-mentioned conditions. The anthocyanin yield was $2.95 \pm 0.08 \mathrm{mg} \cdot \mathrm{g}^{-1}$ with an antioxidant activity yield of $279.96 \pm 0.1 \mu \mathrm{mol} \cdot \mathrm{g}^{-1}$ equivalent of Trolox on a dry weight basis.

The C-3-G content was also optimized using an RSM analysis. The polynomial equation of the quadratic model was as follows:

$\mathrm{Y}=1.43+0.005 \mathrm{X}_{1}+0.43 \mathrm{X}_{2}+0.16 \mathrm{X}_{3}+0.083 \mathrm{X}_{1} \mathrm{X}_{2}+0.14 \mathrm{X}_{1} \mathrm{X}_{3}+0.11 \mathrm{X}_{2} \mathrm{X}_{3}$ $-0.088 \mathrm{X}_{1}^{2}-0.006 \mathrm{X}_{2}^{2}+0.30 \mathrm{X}_{3}^{2}\left(F_{\text {model }}=15.47 ; p<0.05 ; R^{2}=0.965\right)$, where $\mathrm{Y}, \mathrm{X}_{1}, \mathrm{X}_{2}$, and $\mathrm{X}_{3}$ are the yield of $\mathrm{C}-3-\mathrm{G}$, solid to liquid ratio, extraction temperature, and extraction time, respectively.

The maximum C-3-G yield of $2.01 \mathrm{mg} \cdot \mathrm{g}^{-1}$ on a dry weight basis was obtained when using the optimal extraction conditions: solid to liquid ratio, extraction temperature, and time of 1:50, $75.8^{\circ} \mathrm{C}$, and $14.7 \mathrm{~min}$, respectively. The ANOVA statistics showed that the experimental data had correlation coefficient $R^{2}=0.956$ with the calculated model.

The total anthocyanin and C-3-G contents extracted were affected by the three variables studied, but they were most greatly influenced by the extraction temperature. Increased temperature significantly increased the extraction of total anthocyanins and C-3-G (Figure 3), and was able to modify the equilibrium and mass transfer conditions of the solid-liquid extraction. Although higher temperatures had a positive effect on the extraction yields, the temperature cannot be increased indefinitely because of the thermal instability of anthocyanin compounds (Liazid et al., 2011).

The solid to liquid ratio also had an effect on the extraction of total anthocyanins and C-3-G. An increase in the solid to liquid ratio resulted in increased total anthocyanin and C-3-G extraction (Figure 3). At high extract concentrations, the solubility would have increased, and then an increase in the solid to liquid ratio resulted in a greater extraction of the total anthocyanin and C-3-G; however, values increased slowly at
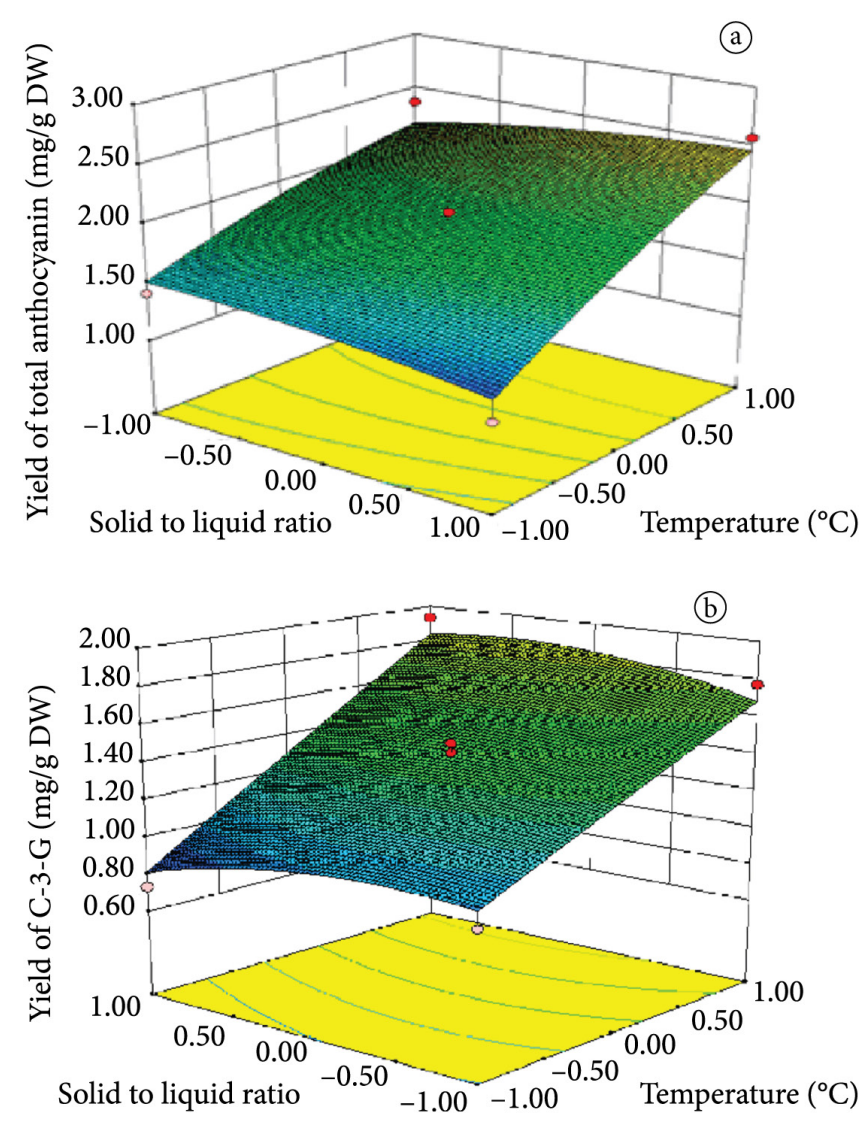

Figure 3. The response surfaces for the effects of temperature and solid to liquid ratio on the yield of total anthocyanin (a) and cyanidin-3-O-glucoside (b).

a high solid to liquid ratio because low extract concentrations would reduce the solubility.

\section{Conclusion}

We first investigated the effect of microwave irradiation on the extracted components. HPLC-DAD-ESI-MS analysis of the extract implied that cyanidin-3-O-glucoside have been hydrolysed to cyanidin during the extraction process. To confirm whether microwave irradiation damaged the anthocyanins, a cyanidin-3-O-glucoside standard was used to evaluate the effects of microwave irradiation on the hydrolysis and release of cyanidin and its antioxidant activity. Our results showed that cyanidin-3-O-glucoside hydrolysed to cyanidin, but the antioxidant activity was not significantly changed during the extraction process featuring high temperature and long extraction times.

Finally, we used the RSM method to optimize the extraction conditions and a positive correlation was found between the total anthocyanin content and antioxidant activity, $R^{2}=0.8431$. The maximum total anthocyanin yield of $2.95 \mathrm{mg} \cdot \mathrm{g}^{-1}$, and an antioxidant activity yield of $279.96 \pm 0.1 \mu \mathrm{mol} \cdot \mathrm{g}^{-1}$ equivalent of Trolox on a dry weight basis were obtained under the optimal conditions where the solid to liquid ratio, extraction temperature, and extraction time were $1: 50,80^{\circ} \mathrm{C}$, and $15 \mathrm{~min}$, respectively, whereas the maximum cyanidin-3-O-glucoside yield of $2.01 \mathrm{mg} \cdot \mathrm{g}^{-1}$ 
on a dry weight basis was obtained under conditions there the solid to liquid ratio, extraction temperature, and extraction time were $1: 50,75.8^{\circ} \mathrm{C}$, and $14.7 \mathrm{~min}$, respectively.

These results provide an important guide for the application of microwave extraction when extracting anthocyanins from plants.

\section{Acknowledgements}

We thank Fangyong Chen for providing the Chinese bayberry materials.

\section{References}

Amr, A., \& Tamini, E. A. (2007). Stability of the crude extracts of Ranunculus asiaticus anthocyanins and their use as food colorants. International Journal of Food Science and Technology, 42, 985-991.

Bao, J., Cai, Y., Sun, M., Wang, G., \& Corke, H. (2005). Anthocyanins, flavonols, and free radical scavenging activity of Chinese bayberry (Myrica rubra) extracts and their color properties and stability. Journal of Agricultural and Food Chemistry, 53(6), 2327-2332. http:// dx.doi.org/10.1021/jf048312z. PMid:15769176.

Chen, K., Xu, C., Zhang, B., \& Ferguson, I. B. (2004). Red bayberry: botany and horticulture. Horticultural Reviews, 30, 83-114.

Des Marais, D. L., \& Rausher, M. D. (2010). Parallel evolution at multiple levels in the origin of hummingbird pollinated flowers in Ipomoea. Evolution, 64(7), 2044-2054. PMid:20148948.

Egizabal, A., Zuloaga, O., Etxebarria, N., Fernandez, L. A., \& Madariaga, J. M. (1998). Comparison of microwave-assisted extraction and Soxhlet extraction for phenols in soil samples using experimental designs. Analyst (London), 123(8), 1679-1684. http://dx.doi. org/10.1039/a802117a.

El-Adawy, T. A. (2002). Nutritional composition and antinutritional factors of chickpeas (Cicer arietinum L.) undergoing different cooking methods and germination. Plant Foods for Human Nutrition, 57(1), 83-97. http://dx.doi.org/10.1023/A:1013189620528. PMid:11855623.

Eskilsson, C. S., \& Björklund, E. (2000). Analytical-scale microwaveassisted extraction. Journal of Chromatography. A, 902(1), 227-250. http://dx.doi.org/10.1016/S0021-9673(00)00921-3. PMid:11192157.

Ganzler, K., Szinai, I., \& Salgó, A. (1990). Effective sample preparation method for extracting biologically active compounds from different matrices by a microwave technique. Journal of Chromatography. A, 520, 257-262. http://dx.doi.org/10.1016/0021-9673(90)85109-9. PMid:2086582.

Gorinstein, S., Leontowicz, H., Leontowicz, M., Namiesnik, J., Najman, K., Drzewiecki, J., Cvikrová, M., Martincová, O., Katrich, E., \& Trakhtenberg, S. (2008). Comparison of the main bioactive compounds and antioxidant activities in garlic and white and red onions after treatment protocols. Journal of Agricultural and Food Chemistry, 56(12), 4418-4426. http://dx.doi.org/10.1021/jf800038h. PMid:18494496.

Heemken, O. P., Theobald, N., \& Wenclawiak, B. W. (1997). Comparison of ASE and SFE with soxhlet, sonication, and methanolic saponification extractions for the determination of organic micropollutants in marine particulate matter. Analytical Chemistry, 69(11), 2171-2180. http://dx.doi.org/10.1021/ac960695f. PMid:21639259.

Kähkönen, M. P., \& Heinonen, M. (2003). Antioxidant activity of anthocyanins and their aglycons. Journal of Agricultural and Food Chemistry, 51(3), 628-633. http://dx.doi.org/10.1021/jf025551i. PMid:12537433.
Kaufmann, B., \& Christen, P. (2002). Recent extraction techniques for natural products: microwave-assisted extraction and pressurised solvent extraction. Phytochemical Analysis: PCA, 13(2), 105-113. http://dx.doi.org/10.1002/pca.631. PMid:12018022.

Kim, D., Jeong, S. W., \& Lee, C. Y. (2003). Antioxidant capacity of phenolic phytochemicals from various cultivars of plums. Food Chemistry, 81(3), 321-326. http://dx.doi.org/10.1016/S0308-8146(02)00423-5.

Kwon, J. H., Bélanger, J. M., \& Paré, J. R. (2003). Optimization of microwave-assisted extraction (MAP) for ginseng components by response surface methodology. Journal of Agricultural and Food Chemistry, 51(7), 1807-1810. http://dx.doi.org/10.1021/jf026068a. PMid:12643634.

Liazid, A., Guerrero, R. F., Cantos, E., Palma, M., \& Barroso, C. G. (2011). Microwave assisted extraction of anthocyanins from grape skins. Food Chemistry, 124(3), 1238-1243. http://dx.doi.org/10.1016/j. foodchem.2010.07.053.

Lopez-Avila, V., Young, R., \& Beckert, W. F. (1994). Microwave-assisted extraction of organic compounds from standard reference soils and sediments. Analytical Chemistry, 66(7), 1097-1106. http://dx.doi. org/10.1021/ac00079a027.

Min, S. W., Ryu, S. N., \& Kim, D. H. (2010). Anti-inflammatory effects of black rice, cyanidin-3-O- $\beta$-D-glycoside, and its metabolites, cyanidin and protocatechuic acid. International Immunopharmacology, 10, 959-966.

Pan, X., Liu, H., Jia, G., \& Shu, Y. Y. (2000). Microwave-assisted extraction of glycyrrhizic acid from licorice root. Biochemical Engineering Journal, 5(3), 173-177. http://dx.doi.org/10.1016/S1369-703X(00)00057-7. PMid:10828417.

Philpott, M., Gould, K. S., Lim, C., \& Ferguson, L. R. (2004). In situ and in vitro antioxidant activity of sweetpotato anthocyanins. Journal of Agricultural and Food Chemistry, 52(6), 1511-1513. http://dx.doi. org/10.1021/jf034593j. PMid:15030203.

Ramirez, J. E., Zambrano, R., Sepúlveda, B., Kennelly, E. J., \& Simirgiotis, M. J. (2015). Anthocyanins and antioxidant capacities of six Chilean berries by HPLC-HR-ESI-ToF-MS. Food Chemistry, 176, 106-114. http://dx.doi.org/10.1016/j.foodchem.2014.12.039. PMid:25624212.

Schantz, M. M., Nichols, J. J., \& Wise, S. A. (1997). Evaluation of pressurized fluid extraction for the extraction of environmental matrix reference materials. Analytical Chemistry, 69(20), 4210-4219. http://dx.doi.org/10.1021/ac970299c.

Sun, Y. Z., Liao, X. J., Wang, Z. F., Hu, X. S., \& Chen, F. (2007). Optimization of microwave-assisted extraction of anthocyanins in red raspberries and identification of anthocyanin of extracts using high-performance liquid chromatography- mass spectrometry. European Food Research and Technology, 225(3-4), 511-523. http:// dx.doi.org/10.1007/s00217-006-0447-1.

Tanaka, Y., Sasaki, N., \& Ohmiya, A. (2008). Biosynthesis of plant pigments: anthocyanins, betalains and carotenoids. The Plant Journal: for Cell and Molecular Biology, 54(4), 733-749. http://dx.doi. org/10.1111/j.1365-313X.2008.03447.x. PMid:18476875.

Vongsangnak, W., Gua, J., Chauvatcharin, S., \& Zhong, J. J. (2004). Towards efficient extraction of notoginseng saponins from cultured cells of Panax notoginseng. Biochemical Engineering Journal, 18(2), 115-120. http://dx.doi.org/10.1016/S1369-703X(03)00197-9.

Yuan, G. F., Sun, B., Yuan, J., \& Wang, Q. M. (2009). Effects of different cooking methods on health-promoting compounds of broccoli. Journal of Zhejiang University. Science. B., 10(8), 580-588. http:// dx.doi.org/10.1631/jzus.B0920051. PMid:19650196. 
Zhang, B., Kang, M., Xie, Q., Xu, B., Sun, C., Chen, K., \& Wu, Y. (2011). Anthocyanins from Chinese bayberry extract protect $\beta$ cells from oxidative stress-mediated injury via HO-1 upregulation. Journal of Agricultural and Food Chemistry, 59(2), 537-545. http://dx.doi. org/10.1021/jf1035405. PMid:21166417.

Zhao, M., Luo, Y., Li, Y., Liu, X., Wu, J., Liao, X., \& Chen, F. (2013). The identification of degradation products and degradation pathway of malvidin-3-glucoside and malvidin-3,5-diglucoside under microwave treatment. Food Chemistry, 141(3), 3260-3267. http:// dx.doi.org/10.1016/j.foodchem.2013.05.147. PMid:23871085.

Zhou, S. H., Fang, Z. X., Lu, Y., Chen, J. C., Liu, D. H., \& Ye, X. Q. (2009). Phenolics and antioxidant properties of bayberry (Myrica rubra Sieb. et Zucc.) Pomace. Food Chemistry, 112(2), 394-399. http://dx.doi.org/10.1016/j.foodchem.2008.05.104. 